Vol.02/ No. 03

Pages: $135-143$

https://www.irojournals.com/itdw/

DOI: https://doi.org/10.36548/jitdw.2020.3.001

\title{
Critical Success Factor of Agile Methodology in Software Industry of Nepal
}

\author{
Prerana Shakya, \\ School of Management Tribhuvan University, Kirtipur, Nepal \\ Email: preranashakya3@gmail.com \\ Subarna Shakya, \\ Pulchowk Campus, Institute of Engineering, \\ Tribhuvan University, Lalitpur, Nepal \\ Email: drss@ioe.edu.np
}

\begin{abstract}
In the modern world, software plays an integral role, following an effective methodology while developing these software have become crucial to accomplish the project goal. Agile approach is a methodology which have been introduced as an effective approach for developing software to increase productivity and efficacy of software development process compare to traditional methodologies. The rapid deployment of solutions, early and continuous delivery of valuable product to the customers, resource utilization, rapid issue detection, customer focus, effective collaboration and communication, adapting changes and flexibility are the key principles of Agile. Meeting the deliverables of the project without compromising its scope, quality and timeline within a limited budget is a key to success. Use of effective project management methodology and identification of critical success factors to achieve project success is essential to understand for any organization whether it is software or non-software.
\end{abstract}

Keywords: Critical Success Factors, Success Factors, Agile, Project Success, Project Deliverables, Software, Project Management Methodology, Software

\section{Introduction}

Project is temporary endeavour undertaken to create a unique product, services or result with definite beginning and ending. Project outcome has tangible or intangible benefits as project is started for achieving objectives within an organizational strategic plan. Project is started to fulfil the market demand, to exploit the business needs, to fulfil customer's demand, to adapt with technological advancement and to collaborate with a legal requirement. Meeting the project's deliverables without compromising its quality, scope, and timeline within a limited budget is a key to project's success. Project management is the most important tool needed in any organization to meet to project deliverables. It is an application of knowledge, skills, tools and techniques that provides better control over financial, physical and human resources. It helps to improve customer relations by increasing productivity, reliability and providing higher quality products to the customer. Recently, most of the software based company have incorporated Agile, a project management methodology for effective and efficient development of projects. The rapid deployment of solutions, early and continuous delivery of valuable product to the customers, resource utilization, rapid issue detection, customer focus, effective collaboration and communication, adapting changes and flexibility are the key principles of Agile. Analysing the critical success factors of agile methodology in various software company of Nepal is the main objective of this research.

In a present context, by the growing demand of information technology, the software has become one of the major and essential aspect in this modern world. In an era, where the world is experiencing augmented reality, playing with Internet of things and other latest trending technologies (Webpreneurs Hub, 2018), Nepal is still lagging behind. Although we are taking small steps in technological advancement, we are moving in a same direction to facilitate the people with all latest technology trends via ecommerce, digital wallet, internet broadband, online business, gaming, entertainment and many more. Various small, medium and large software enterprises are developing in Nepal in order to meet the software demand of customers. Many of the companies are growing, providing a quality and satisfying services to the customers. However, the effective and efficient management of the software project and selecting and implementing the appropriate software development process is still a challenge to the most of the software companies of Nepal. These problems cause rejection in a final product (software), delays in delivery time, abandoning products to reach to their customers. Even software projects which

Information Technology $\&$ 
Journal of Information Technology and Digital World (2020)

Vol.02/ No. 03

Pages: $135-143$

https://www.irojournals.com/itdw/

DOI: https://doi.org/10.36548/jitdw.2020.3.001

are successfully finished and are already applied in systems may need expensive continuously maintenance support or other software services and fine release (Nasehi, 2013).

Many of the software company have incorporated the agile methodology as the software development process with an objective to create business value and delivering working software to end user constantly at regular short time intervals. But the agile itself consist of many challenges which most of the company fails to handle. The company fails to understand what actually the agile process is. The critical success factors of agile methodology that were assumed to bring success to the project doesn't seem to be effective enough because of the lack of proper analysis and strategic planning. This research study aims to identify and provide insight into success factors of agile methodology that will help software development projects to complete the development process with more accomplishment (Nasehi, 2013).

\section{Related Works}

While software is so important for the all facets of the modern world, software development itself is not a perfect process. Despite the efforts to employ software engineering methodologies, software development has not been consistently successful, thus often resulting in delayed, failed, abandoned, rejected software projects (Tsun Chow, 2008). A large percentage of failures in software projects are caused by inability of involved people to provide effective software solutions as per the desired requirement, the vague and unclear requirements, lack of strategic and tactical planning, lack of effective and efficient project management tools and software engineering processes. The range of above failures has been the centre of attention for many managers, engineers and researchers to implement process of software development. The implementation of proper software development processes in a company helps managers and other stakeholders to cope with the above mentioned problems and at the same time can enable them to take strategic planning and decisions for the growth and success of the business.

\subsection{Critical Success Factors}

Critical Success Factor is introduced as an approach which detects names and evaluates an organization's performance. This approach was first explained by Rockhart (1979) and after that year was developed and became established in better way (Bullen \&Rockart, 1981). Critical Success Factor is explained by Bullen.C.V and Rockart.J.F. (1981) as limited number of domains in which real satisfaction will result and ensure accomplishment especially in competitive performance for all individuals, departments and organization. Critical success factors are key areas where every things are supposed to be done in right method through business process in order to flourish the accomplishment and in order to achieve manager's goals (Nasehi, 2013). In software development project area, the Critical Success Factors method has also been considered in recent studies. Critical success factors in development projects are usually found to be relevant to project management techniques basis or to relevant to the combination of software development and business strategy (Bytheway, 1999). Another research works explains that Critical success factors in software development projects contains variety of dimensions, start from the development life cycle, estimation and validation and end to executive management and project management, or resource management and strategic planning (Boghossian, 2002). The search for the success and failure factors in agile adoption is started in 1996 when Walid and Oya recommended new framework to decide critical success and failure elements. They have recommended new framework for basic factors and the effect of these factors on the effective and efficient contribution on achieving project success. Empirical study had been utilized by them to test the practicality of utilizing the recommended design. They have divided the factors into 4 groups, project, managers and team members, organization, and environment. Additionally, the result of the survey demonstrate that project managers' managerial skills, team members' commitment and their technical background, project attributes and environmental factors are as viable and can be as critical as the organizational factors, although the criticality of these factors varies between industries (Belassi\&Tukel, 1996).

Moreover, there was a survey done by Tsun chow, Dac-Buu Cao in 2008 to study the success factors in agile software ventures by utilizing quantitative approach. The research study set out to use survey data to explore the critical success factors of agile software development projects using quantitative methods. The data collected from 109 agile projects from a diverse group of organizations of various sizes, industries, and geographic locations provided enough empirical information for statistical analysis to arrive at a number of conclusions. Out of 48 research hypotheses, only 10 are supported. Through multiple regression analysis, the only factors that could be called critical success factors are found to be (a) a correct delivery strategy, (b) a proper practice of agile software engineering techniques, and (c) a high-calibre team. Three other factors that could be critical to certain success dimensions are found to be (a) a good agile project management process, (b) an Agile-friendly team environment, 
Journal of Information Technology and Digital World (2020)

Vol.02/ No. 03

Pages: $135-143$

https://www.irojournals.com/itdw/

DOI: https://doi.org/10.36548/jitdw.2020.3.001

and (c) a strong customer involvement (Tsun Chow, 2008). In attempting to check the rating of crucial success factors which were described previously in the review done by Chow and Cao (2008). They used a regression analysis for the gathered information which presented three more factors that could conceivably be considered as basic success factor (Stankovic, Nikolic, Djordjevic, \& Cao, 2013). Chow and Cao (2008) presented a research model that illustrated how organizational, people, process, technical, and project factors were used as groups of independent variables to study their relationship with perceived success of the agile software development project as evaluated by quality, scope, time, and cost. Later on Totten (2017), considered same independent variables but defined perceived success into 11 dependent variables. The foursignificant independent variables shown to predict project success in his research study were (1) commitment by management with a clear vision, (2) holding daily stand-up meetings, (3) keeping task sizes small, and (4) using visual management (Totten, 2017).

\section{Proposed Work}

The overall premise of my research study was to analyse the various critical success factors of agile methodology and provide insight on how the success factors influence on the success of overall business and enable manager's to achieve organizational goals. This section describes the conceptual framework for carrying on overall research. The conceptual framework can have both theoretical and practical contributions. In terms of theoretical contributions, the results build on a knowledge management perspective can provide a fresh view synthesizing various factors that can potentially influence acceptance of agile methodologies. In terms of practical contributions, the framework can consolidate current knowledge on acceptance of agile methodologies which can provide guidance to organizations interested in getting their developers to use these new methodologies (Kaur \& Singh, 2016).

The following figure shows the conceptual framework of overall research purpose. The conceptual framework in figure 7 has been developed on the ideas of theories described in the review of existing literature. In this study, I have revised the existing conceptual framework defined by multiple researched (chapter 3) to make it reliable for Nepal's software company. I have categorized factors into 6 dimensions i.e. Organization, human resource and technical factors and termed it as an independent variables. Each of these factors have taken a coarse-grained approach by aggregating a subset into one single CSF, while has considered the factors in finer granularity (Garousi, Tarhan, Pfahl, Coşkunçay, \&Demirörs, 2018) i.e. 26 success factors of agile development were identified which were translated into 26 main hypotheses. For example, "Team factor" has been considered as one single factor and team capability, team cooperation and collaboration, team size and enhancement of team capability through training has considered factor in finer granularity. Additionally, preliminary study is conducted to narrow down the dependent variables (perceived project success) defined by Totten and identified top 6 perceived project success in context of software companies of Nepal. All of these success factors are assumed to have a significant relationship with perceived project success.

\subsection{Dimension of Agile based on factors}

\subsubsection{Organizational Factors}

On studying and analysing numbers of research papers regarding CSF, there exist number of subset that comes under the organization dimension. However, for this research, I have focused in five major finer granularity for this dimension i.e. organization working culture, organization structure, proper business processes, relationship between client and vendors and support from top management. And have assumed these factors as a CSF that contributes in achieving project success via successful implementation of agile practice.

\subsubsection{Environmental Factors}

On studying and analysing numbers of research papers regarding CSF, there exist number of subset that comes under the environmental dimension. However, for this research, I have focused in four major finer granularity for this dimension i.e. economic, political, legal and physical security. And have assumed these factors as a CSF that contributes in achieving project success via successful implementation of agile practice.

Information Technology \&

Digital World 
Journal of Information Technology and Digital World (2020)

Vol.02/ No. 03

Pages: $135-143$

https://www.irojournals.com/itdw/

DOI: https://doi.org/10.36548/jitdw.2020.3.001

\section{INDEPENDENT VARIABLES}

Organizational Factor

1. Organization working Culture

2. Organization structure

3. Proper Business Processes

4. Relationship between client and vendors

5. Support from top management

\section{Environmental Factor}

1. Legal Environment

2. Political Environment

3. Physical Security

4. Economic Environment

\section{DEPENDENT VARIABLES}

Technical Factor

1. Proper planning and formulation of project delivery strategies

2. Backlog prioritization

3. Daily standup meeting

4. Maintaining a short iteration of project

5. Configuring necessary PM tools and techniques

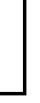

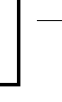
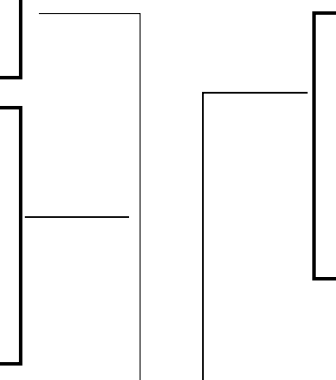

\section{Control Variables}

1. Support from Client

2. Types of Project Contract

3. Types of Client

\section{Perceived Project Success}

1. On-time Delivery

2. Improved Quality Product

3. Customer Satisfaction

4. Improved managerial effectiveness

5. Ability to react to change

6. Reduced project risk

\section{Project Factor}

1. Proper project planning and management

2. Minimum change of requirement

3. Formulating effective development process

4. Project Complexity

5. Project Size

\section{Team Factor}

1. Team capability

2. Team corporation and collaboration

3. Size of the team

4. Enhancement of team capability through training

\section{Customer Factor}

1. Customer Involvement

2. Customer Satisfaction

3. Customer Relationship

Figure 1: Proposed Conceptual Framework for Critical Success Factors 
Journal of Information Technology and Digital World (2020)

Vol.02/ No. 03

Pages: $135-143$

https://www.irojournals.com/itdw/

DOI: https://doi.org/10.36548/jitdw.2020.3.001

\subsubsection{Technical Factors}

On studying and analysing numbers of research papers regarding CSF, there exist number of subset that comes under the technical dimension. However, for this research, I have focused in five major finer granularity for this dimension i.e. Proper planning and formulation of project delivery strategies, Backlog prioritization, Daily standup meeting, Maintaining a short iteration of project and Configuring necessary PM tools and techniques. And have assumed these factors as a CSF that contributes in achieving project success via successful implementation of agile practice.

\subsubsection{Project Factors}

On studying and analyzing numbers of research papers regarding CSF, there exist number of subset that comes under the project dimension. However, for this research, I have focused in five major finer granularity for this dimension i.e. Proper project planning and management, Minimum change of requirement, Formulating effective development process, Project Complexity and Project Size. And have assumed these factors as a CSF that contributes in achieving project success via successful implementation of agile practice.

\subsubsection{Team Factors}

On studying and analyzing numbers of research papers regarding CSF, there exist number of subset that comes under the team dimension. However, for this research, I have focused in four major finer granularity for this dimension i.e. team capability, team cooperation and collaboration, team size and enhancement of team capability through training. And have assumed these factors as a CSF that contributes in achieving project success via successful implementation of agile practice.

\subsubsection{Customer Factors}

On studying and analyzing numbers of research papers regarding CSF, there exist number of subset that comes under the customer dimension. However, for this research, I have focused in three major finer granularity for this dimension i.e. customer involvement, customer satisfaction and customer relationship. And have assumed these factors as a CSF that contributes in achieving project success via successful implementation of agile practice.

\subsection{Perceived Project Success}

In this research, I have considered 10 variables as a dependent variable. The CSF (independent variables) that I have defined above are assumed to have a significant effect on achieving the project success. "On-time Delivery, Improved Quality Product, Customer Satisfaction, Increased Revenue, Improved Managerial Effectiveness, Improved Employee Engagement, Ability to React to Change, Reduced Project Risk, Improved Project Visibility and Improved Team's Dynamics are the dependent variables (Totten, 2017).

\subsection{Control Variables}

Three factors are selected as control variables in successful implementation of agile process improvement 1) Support from clients. Without their understanding, support and cooperation, agile software process is difficult to successfully implement 2) Types of project contract. It's more difficult to implement if fixed price contract is used in some project. 3) Types of clients. The type of clients also creates difficulty to successfully implement agile process (Wan \& Wang, 2010). All these three are the control variables that are assumed to have an impact on successful implementation of Agile.

\section{Results and Discussions}

The key findings of the overall research includes the understanding and implementation of agile methodology in the software company of Nepal and the analysis of key success factors to achieve perceived project success. The findings of the research questions are summarized below.

\subsection{Findings Related to RQ 1 (a)}

The first research question asked, what is the understanding of agile methodologies among the employees of the software company? The total of 193 responses from the participants from various software companies of Kathmandu valley have been collected. Among those, 15 responses have been excluded as they failed to meet the survey criteria. 15 of them answered, they have no experience working in agile environment. However, from above demographic data, I was able to draw the answer for my first research question. Among 178 participants, 
Journal of Information Technology and Digital World (2020)

Vol.02/ No. 03

Pages: $135-143$

https://www.irojournals.com/itdw/

DOI: https://doi.org/10.36548/jitdw.2020.3.001

130 participants i.e. $73.24 \%$ have good understanding in agile methodologies and have experience working in agile environment and 21 participants i.e. $11.3 \%$ have little understanding of agile methodologies. Among 178 employees, $48.3 \%$ have $4-10$ years of working experience in agile environment and $48.7 \%$ are software engineers, $25.3 \%$ are Project Managers and 15.2\% are QCs.

\subsection{Findings Related to RQ 1 (b)}

The second research question asked to what extent, and how are companies using agile methodologies to develop software? So, on analysing the demographic data, the software company with more the 150 employees has been implementing agile above $75 \%$ and maximum of them i.e. around $86 \%$ of total sample has adopted Scrum as an agile methodology, followed by Kanban which is $48.4 \%$ of total sample.

\subsection{Findings Related to RQ 2}

The regression analysis gives the answer of $\mathbf{R Q} \mathbf{2}$, what are the critical success factors that contributes in predicting project success via successful implementation of agile development methodology? From the result obtained, except environmental factors, all other factors, organizational ( $p$-value: 0.000), technical (p-value: 0.001), project (p-value: 0.038), team (p-value: 0.047) and customer factors (p-value: 0.000) came to be the critical success factors that contributes in achieving project success via successful implementation of agile development methodology.

\subsection{Findings Related to RQ 3}

The third research question asked to what extent, organizational, environmental, technical, project, team and customer factors predict the perceived level of success when agile methodology is implemented efficiently? This research question is designed to get the answer on which of the independent variables (i.e. CSF) were significant in predicting project success when agile methodology is implemented efficiently in Software Company of Nepal. Prior, the participants were asked a question to select top 6 project success from 10 choices. They have selected their top 6 choices, which they believe are the perceived project success achieved if agile is successfully implemented. Hence, project success was defined by 6 dependent variables:

1. Improved quality product

2. On-time delivery

3. Customer satisfaction

4. Reduced project risk

5. Ability to react to change

6. Improved managerial effectiveness

Then individual independent variables were analysed to determine its significance in predicting any of the individual dependent variable. To be significant the regression analysis was done and required to have a p-value equal to or less than 0.05 .

Among 25 independent variables, only 11 independent variables showed significance below p-value 0.05 . Table 1 summarizes the significance for each of the 11 independent variables as tested against individual dependent variables. The independent variables that were significant predictor for the most of the dependent variables were "Organizational Structure", "Implementation of proper business process", "Team Capability" and "Customer Involvement on a Project" (3 of 6 dependent variables). "Organizational working culture", "Daily stand-up meeting", "Configuring PM tools and techniques" and "Size of project" being next ( 2 of 6 dependent variables). And "Economic environment", and "Backlog prioritization" being last ( 1 of 6 dependent variable). 
Journal of Information Technology and Digital World (2020)

Vol.02/ No. 03

Pages: $135-143$

https://www.irojournals.com/itdw/

DOI: https://doi.org/10.36548/jitdw.2020.3.001

Table 1: Significant Independent Variables Predicting Dependent Variables

\begin{tabular}{|c|c|c|c|c|c|c|c|}
\hline & & Dependen & Variables & & & & \\
\hline Factors & $\begin{array}{l}\text { Independent } \\
\text { Variables } \\
\\
\quad \text { Predicts }\end{array}$ & $\begin{array}{l}\text { Improved } \\
\text { Quality } \\
\text { Product }\end{array}$ & $\begin{array}{l}\text { On-time } \\
\text { Delivery }\end{array}$ & $\begin{array}{l}\text { Customer } \\
\text { Satisfaction }\end{array}$ & $\begin{array}{l}\text { Reduced } \\
\text { Project } \\
\text { Risk }\end{array}$ & $\begin{array}{l}\text { Ability to } \\
\text { react to } \\
\text { change }\end{array}$ & $\begin{array}{l}\text { Improved } \\
\text { managerial } \\
\text { effectivenes } \\
\mathrm{s}\end{array}$ \\
\hline \multirow[t]{4}{*}{$\begin{array}{l}\text { Organizational } \\
\text { Factor }\end{array}$} & $\begin{array}{l}\text { Organizational } \\
\text { working culture }\end{array}$ & & & & & & \\
\hline & $\begin{array}{l}\text { Organizational } \\
\text { Structure }\end{array}$ & & & & & & \\
\hline & $\begin{array}{l}\text { Implementation of } \\
\text { proper business } \\
\text { process }\end{array}$ & & & & & & \\
\hline & $\begin{array}{l}\text { Support from top level } \\
\text { management }\end{array}$ & & & & & & \\
\hline $\begin{array}{l}\text { Environmental } \\
\text { Factor }\end{array}$ & $\begin{array}{l}\text { Economic } \\
\text { environment }\end{array}$ & & & & & & \\
\hline \multirow{3}{*}{$\begin{array}{l}\text { Technical } \\
\text { Factor }\end{array}$} & Backlog prioritization & & & & & & \\
\hline & Daily Standup Meeting & & & & & & \\
\hline & $\begin{array}{l}\text { Configuring necessary } \\
\text { PM tools and } \\
\text { techniques }\end{array}$ & & & & & & \\
\hline Project Factor & Size of project & & & & & & \\
\hline Team Factor & Team Capability & & & & & & \\
\hline $\begin{array}{l}\text { Customer } \\
\text { Factor }\end{array}$ & $\begin{array}{l}\text { Customer involvement } \\
\text { on a project }\end{array}$ & & & & & & \\
\hline
\end{tabular}

Additionally, "Implementation of proper business process" is an independent variable that is predicted to have the greatest impact on "improved quality product." Similarly, "Team capability" is predicted to have greatest impact on "on time delivery", "Customer involvement on a project" is predicted to have greatest impact on "Customer satisfaction", "Customer involvement on a project" is predicted to have greatest impact on "reduced project risk", "Size of project" is predicted to have greatest impact on "ability to react to change" and finally "Configuring necessary PM tools and techniques" is predicted to have greatest impact on "improved managerial effectiveness".

Therefore, from the above analysis, it is clear that except "Support from top level management" all above listed 10 independent variables can be considered as a critical success factors that contributes on achieving perceived project success via successful implementation of agile methodology in the software company of Nepal.

\section{Conclusion}

The result of this research revealed the understanding of employees working on software companies of Nepal on agile methodology. The most of the software companies of Nepal are using agile methodology for managing software projects. Scrum and Kanban being the most commonly used agile methodology for meeting project deliverables successfully. Through this research, the critical success factors of agile methodology was determined 
Journal of Information Technology and Digital World (2020)

Vol.02/ No. 03

Pages: $135-143$

https://www.irojournals.com/itdw/

DOI: https://doi.org/10.36548/jitdw.2020.3.001

along with its relationship with project success. The result obtained from the inter-correlation between perceived success (PS) and other independent variables suggest that there is positive and significant relationship between PS and OF, EF, TEF, PRF, TMF and CF. Among these OF, TEF, TMF and CF found to have high and positive correlation with PS. Then on the basis of regression analysis it is found that OF, TEF, PRF, TMF and CF are the critical success factors that contributes in predicting project success via successful implementation of agile development methodology. All these factor showed positive and significant impact on dependent variable i.e. perceived success, hence, accepting the hypothesis.

Additionally, the backward regression analysis technique is carried on to eliminate non-significant independent variables. And regression analysis is carried to predict the impact of each significant independent variable i.e. success factors on individual dependent variable. Further considering and analyzing the factors in finer granularity, organizational working culture, organizational structure,implementation of proper business process, economic environment, backlog prioritization, daily standup meeting, configuring necessary PM tools and techniques, size of project, team capability and customer involvement on a project came out to be the most significant critical success factors.

Therefore, will help top level management and project managers to focus on these success factors since it will contribute on achieving perceived project success via successful implementation of agile methodology in Software Company of Nepal.

\section{References}

[1] Webpreneurs Hub. (2018, April 20). Retrieved from Latest Technology Trends in Nepal:http://webpreneurshub.com/latest-technology-trends-in-nepal/.

[2] Anand, J. V. "Design and Development of Secure and Sustainable Software Defined Networks." Journal of Ubiquitous Computing and Communication Technologies (UCCT) 1, no. 02 (2019): 110-120.

[3] Nasehi, A. (2013). A Quantitative Study on Critical Success Factors in Agile Software Development Projects;Case Study IT Company

[4] Tsun Chow, D.-B. C. (2008). A survey study of critical success factors in agile software projects.Journal of Systems and Software,81(6), 961-971.

[5] Raj, Jennifer S., and S. Smys. "Virtual Structure for Sustainable Wireless Networks in Cloud Services and Enterprise Information System." Journal of ISMAC 1, no. 03 (2019): 188-205.

[6] Bullen, C. V., \& Rockart, J. F. (1981). A Primer on critical success factors, Information Systems Research no.69.

[7] Bytheway, A. J. (1999). Successful software projects and how to achieve them. IEEE Software, 16 (3). 1517.

[8] Boghossian, Z. J. (2002). An investigation into the critical success factors of software development process, time, and quality, Ph.D. Thesis,Pepperdine University, Malibu, California

[9] Belassi, W., \& Tukel, O. I. (1996). A new framework for determining critical success/failure factors in projects. International Journal of Project Management, 14(3), 141-151.

[10] Joby, P. P. "Exploring Devops: Challenges and Benefits." Journal of Information Technology 1, no. 01 (2019): 27-37.

[11] Stankovic, D., Nikolic, V., Djordjevic, M., \& Cao, D.-B. (2013). A survey study of critical success factors in agile software projects in former Yugoslavia IT companies.Journal of Systems and Software, 86(6), $1663-1678$.

[12] Kaur, N., \& Singh, G. (2016). A Quantitative Study on Critical Success Factors in Agile Software Development Projects.International Journal of Electrical, Electronics and Computer Engineering, 5(1), 18.

[13] Pandian, M. Durai. "Enhanced Network Performance and Mobility Management of IoT Multi Networks." Journal of trends in Computer Science and Smart technology (TCSST) 1, no. 02 (2019): 95105 . 
Journal of Information Technology and Digital World (2020)

Vol.02/ No. 03

Pages: $135-143$

https://www.irojournals.com/itdw/

DOI: https://doi.org/10.36548/jitdw.2020.3.001

[14] Garousi, V., Tarhan, A., Pfahl, D., Coşkunçay, A., \& Demirörs, O. (2018). Correlation of critical success factors with success of software projects: an empirical investigation. Software Quality Journal, 27, 429493.

[15] Totten, Jeff, "Critical Success Factors for Agile Project Management in Non-Software Related Product Development Teams" (2017). Dissertations. 3178.

[16] https://scholarworks.wmich.edu/dissertations/3178.

[17] Karthiban, Mr K., and Jennifer S. Raj. "Big data analytics for developing secure internet of everything." Journal of ISMAC 1, no. 02 (2019): 129-136.

[18] Wan, J., \& Wang, R. (2010). Empirical Research on Critical Success Factors of Agile Software Process Improvement.Journal of Software Engineering and Applications, 3(12), 1131-1140.

\section{Authors Biography}

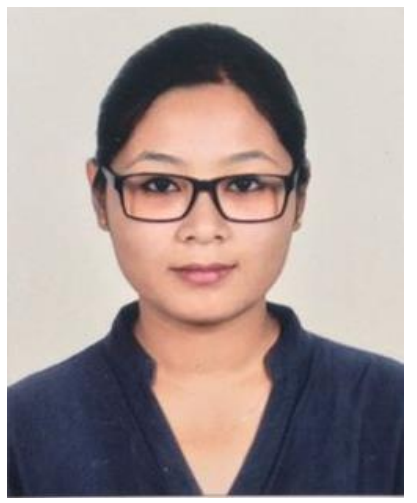

PRERANA SHAKYA had completed her MBA in Information Technology from School of Management Tribhuvan University, Kirtipur, Nepal, 2018. She had received her Bachelor degree in Computer Engineering from Acme Engineering College, Purbanchal University, Kathmandu, Nepal in 2014. She had worked in Deerwalk Inc. Sifal as a Software Engineer for 2 years, NITV Nepal, Naxal as an Associated Project Manager for 1 year and currently working as an Associate Project Manager in Fusemachines Nepal, Kamladi since 2019.

Her area of research interest includes agile project management, key success factors, and Project management methodologies in context of Nepal

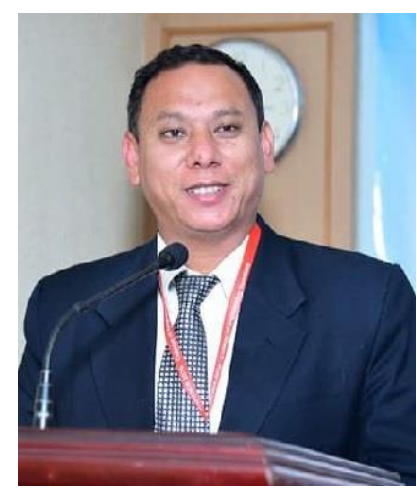

SUBARNA SHAKYA has received the MSc and $\mathrm{PhD}$ degrees in Computer Engineering from the Lviv Polytechnic National University, Ukraine, 1996 and 2000 respectively. He is the Professor of Computer Engineering, Department of Electronics and Computer Engineering, Pulchowk Campus, Institute of Engineering, Pulchowk, Tribhuvan University, Nepal. He has served as Executive Director at National Information Technology Centre, Government of Nepal. . He was awarded 100 most dedicated professors, $4^{\text {th }}$ July, 2019 and also awarded best professor in Computer Engineering studies, 10 $0^{\text {th }}$ Dec 2019 by World education congress.

His areas of research interests include E-Government system, Computer Systems \& Simulation, Cloud computing \& security, Software Engineering \& Information System, Computer Architecture, Multimedia system. 